Io sugieren también la evidente enemistad personal, y la queja de AveIlaneda de que Cervantes lo había ofendido en la primera parte del Quijote ${ }^{28}$.

Las sugerencias que hago aquí con respecto a Avellaneda son tentativas, algo inevitable, creo, en el caso de una obra sobre la que se conoce tan poco con certeza. Pero la composición en 1605 de un tercio de la segunda parte de Cervantes es la única forma de interpretar coherentemente los comentarios sobre la primera que nos da el texto.

Daniel Eisenberg

Florida State University.

\title{
LOS DOS COMIENZOS DE LA HISTORIA DE CARDENIO
}

EI largo episodio (o novela) de los amores de Cardenio y de Dorotea ha merecido un interés erudito (en relación, especialmente, con su adaptación en el teatro isabelino) o temático, dentro de estudios globales del Quijote ${ }^{1}$. La personalidad misma de Cardenio ha llamado la atención como característica de un temperamento morboso ${ }^{2} \mathrm{y}$, recientemente, Gilman ha tratado sobre la función de su historia en relación con la idea cervantina de la comedia como equivalente de la novela de caballería ${ }^{3}$.

libro; véase A. SÁNchez, “¿Consiguió Cervantes identificar al falso Avellaneda?", ACerv, 2 (1952), 311-333.

28 "Tomó por tales [medios] el ofender a mi", ed. de Riquer, I, p. 9. E1 estudio más actual y convincente de esta ofensa de la primera parte es el de Riquer, "El Quijote y los libros", PSA, 54 (1969), 5-24.-Ya escrito este trabajo, he visto la nota de Nicolás Marín, "Lope y el prólogo del Quijote apócrifo", Ins., 1974, núm. 336, en la cual propone que fue Lope, y no Avellaneda, el autor del prólogo a la espuria segunda parte. La tesis es interesante y la diferencia de estilo entre el prólogo y la obra de Avellaneda es evidente; sin embargo, no me convence la teoría de Marín de que Avellaneda intentó emular sinceramente a Cervantes, y quedan entonces sin explicación los "sinónimos voluntarios" de Cervantes que tanto ofendieron al autor del prólogo de la novela de Avellaneda.-No he podido ver todavía otro trabajo de Marín, "La piedra y la mano en el prólogo del Quijote apócrifo", en Homenaje a Guillermo Gustavino, Madrid, 1974, pp. 253-288.

1 Para la historia de las fuentes y las imitaciones de la novela de Cardenio, véase Raymond L. Grismer, Cervantes: A bibliography, New York 1946, t. 1, índices, y Dámaso Alonso, "Lope, Pedro de Cárdenas y los Cardemios", $R F E, 40$ (1956), 67-90. Entre los estudios temáticos más recientes se destaca el de ArTHur EfroN, Don Quixote and the dulcineated world, University of Texas Press, 1971, pp. 125 ss., en cuanto a la estilización de la vida como constante del Quijote. Algunos críticos han tratado más o menos directamente la cuestión de la importancia de la historia de Cardenio en relación con la de don Quijote; véase especialmente E. C. RiLeY. "Episodio novela y aventura en Don Quijote", ACerv, 5 (1955-56), 209-230, con la bibliografía pertinente.

2 Véase Alan S. Trueblood, "El silencio en el Quijote", NRFH, 12 (1958), es. pecialmente p. 632 .

3 La conclusión del crítico es que la historia de Cardenio representa "la imposibilidad de cumplir con un papel literario -en este caso, social-literario [pues] 
La meta de las páginas que siguen es examinar cómo introduce Cervantes a Cardenio en la trama del Quijote (I, 23), su desaparición y reaparición varios capítulos después. A través de este proceso la acción narrativa se ve afectada por la dificultad de Cardenio para adoptar el papel que mejor le conviene de acuerdo con el argumento de su historia - "amante de capa y espada" (Gilman, p. 19) -, porque tampoco Cervantes parece estar convencido de la necesidad de que sea Cardenio sólo eso, quizá porque no está seguro, al menos en el primer Quijote, sobre el papel de las varias tradiciones literarias que componen la materia del libro.

La aparición de Cardenio ocurre a través del soneto con quejas amorosas que halla don Quijote en la maleta abandonada: "y a fe que debe de ser razonable poeta, o yo sé poco del arte" 4 , sentencia el caballero, enmarcando al futuro Cardenio en un mundo erótico-literario de carácter pastoril, según sugiere el escenario de la sierra y confirman a continuación la carta -versión en prosa de las mismas quejas del soneto- y otros versos y cartas que contenían "quejas, lamentos, desconfianzas, sabores y sinsabores, favores y desdenes, solenizados los unos y llorados los otros" (p. 322). Cardenio podría ser a esta altura un nuevo Grisóstomo, aun cuando el resto del contenido de la maleta (un atadito de escudos de oro, cuatro camisas de holanda y otras piezas de lienzo) apunta a un viajero común y corriente, pues es sabido que la pastoril española no excluye la realidad cotidiana 5 .

Es el hallazgo de los versos y quejas de Cardenio lo que, de hecho, sugiere directamente a don Quijote imitar la penitencia amorosa de Amadís que llevará a cabo más tarde ${ }^{6}$, pues cuando penetra en la sierra sólo piensa en aventuras caballerescas a tono con aquellas soledades; en tanto que al leer el soneto y preguntarle Sancho si también entiende de poesía, responde orgullosamente que ya lo comprobará, "cuando lleves una carta, escrita en verso de arriba abajo, a mi señora Dulcinea del Toboso" (p. 321).

Don Quijote queda con gran deseo de conocer al "principal enamorado" (p. 323), pero en lugar de éste, ve a poco una especie de

en el medio social de Cardenio, las personas se comprenden y tratan como libros... o personajes de comedias. Sin habérselo propuesto locamente como don Quijote, Cardenio no encuentra otro modelo que el de amante de capa y espada. Y es su inhabilidad de interpretar bien este papel, su incapacidad de encarnar el caba. lleresco exhibicionismo exigido por aquella sociedad ávida de literatura exaltada, en una palabra, el hecho de que no servia para galán, eso es lo que animaba y a la vez aniquilaba su vida" (STEPHEN Gilman, "Los inquisidores literarios de Cervantes", $C H(3)$, p. 19) .

4 Obras completas, Don Quixote de la Mancha, ed. Schevill y Bonilla, Madrid, 1928 , t. 1, p. 320. Todas las citas provienen de esta edición. He modernizado la ortografia.

5 Sobre este aspecto de la novedad de la Diana y, en general, de la literatura pastoril española, véase Carroll B. Johnson, "Montemayor's Diana: a novel pastoral", BHS, 48 (1971), 20-35, y ANThony T. PerRy, "Ideal love and human realism in Montemayor's Diana", PMLA, 84 (1969), 227-234.

6 Aunque hay antes una mención de la penitencia de la Peña Pobre (I, 15, p. 203), don Quijote "parece ser influido inconscientemente por el ejemplo de Cardenio al emprender su penitencia - por otra parte imitación consciente de Amadís" (RILEY, art. cit., p. 215). 
hombre-mono, saltando "de risco en risco y de mata en mata con extraña ligereza. Figurósele que iba desnudo, la barba negra y espesa, los cabellos muchos y rabultados, los pies descalzos y las piernas sin cosa alguna; los muslos cubrían unos calzones, al parecer de terciopelo leonado, mas tan hechos pedazos, que por muchas partes se le descubrían las carnes" (loe. cit.). De la lectura de sus versos a su aparición física, el dueño de la maleta ha dejado de ser un melancólico pastor enamorado y recuerda más bien aquellos salvajes semidesnudos que atacan a las ninfas en la Diana (Lib. II, ed. Clás. cast., p. 89) .

Cervantes continúa acrecentando en nosotros el interés por conocer al loco enamorado con la muía muerta que hallan don Quijote y Sancho unos pasos más allá, hasta que por fin un cabrero les cuenta cómo había llegado por aquellos parajes, hacía ya medio año, un gentil mancebo, que se internó por la parte más escondida del monte y salió sólo unos días después para atacar a un pastor a coces y puñadas y robarle pan y queso. A los cabreros que salen a buscarlo, Cardenio les explica llorando y "con mucha mansedumbre" (p. 327) que andaba de ese modo porque "así le convenía para cumplir cierta penitencia que por sus muchos pecados le había sido impuesta" (p. 328), hasta que "estando en lo mejor de su plática, paró y enmudecióse; clavó los ojos en el suelo por un buen espacio, en el cual todos estuvimos quedos y suspensos, esperando en qué había de parar aquel embelesamiento, con no poca lástima de verlo, porque lo que hacía de abrir los ojos, estar fijo mirando al suelo sin mover pestaña gran rato, y otras veces cerrarlos apretando los labios y enarcando las cejas, fácilmente conocimos que algún accidente de locura le había sobrevenido. Mas él nos dio a entender presto ser verdad lo que pensábamos, porque se levantó con gran furia del suelo donde se había echado, y arremetió con el primero que halló junto a sí, con tal denuedo y rabia, que, si no se le quitáramos, le matara a puñadas y a bocados; y todo esto hacía diciendo: "Ah, fementido Fernando!; ¡aquí, aquí me pagarás la sinrazón que me hiciste!»" (p. 329). Cardenio vuelve a internarse en el monte y sigue apareciendo cuando padece hambre, unas veces a pedir de comer y otras, cuando "está con el accidente de la locura", a arrebatarlo.

El penitente de amor ha tomado la decidida apariencia de un loco, cuya conducta se describe con curioso detalle. Entonces surge Cardenio mismo, "el cual venía hablando entre sí cosas que no podían ser entendidas de cerca, cuando más de lejos" (p. 331); insistiéndose en seguida en la posición social que sugieren sus harapos.

El loco debe atraer, por afinidad espiritual, a don Quijote si atendemos a su encuentro, cuando se saludan con un largo abrazo, "como si de luengos tiempos le hubiera conocido" [don Quijote a Cardenio], y se contemplan luego detenidamente "el Roto de la Mala Figura" y "el de la Triste" (p. 331), según bautizó al caballero su escudero en el capítulo 19.

Las primeras palabras que cruzan los nuevos amigos suenan a saludos de caballeros andantes, con su característico ofrecimiento de servicio y exageraciones de cortesía; de caballeros andantes enamorados y en desgracia, pues Cardenio se lamenta de que su situación no le 
permita corresponder a las ofertas de don Quijote, y éste le promete que si no puede consolarlo, llorará con él en cuanto sepa la causa de sus desgracias. Cardenio - a quien ahora se llama "El Caballero del Bosque" (p. 334) - va a responder con la narración de sus desventuras, pero primero pide algo de comer, y lo devora "tan apriesa, que no daba espacio de un bocado al otro, pues antes los engullía que tragaba; y en tanto que comía, ni él ni los que le miraban hablaban palabra" (loc. cit. $)^{-}$. Luego de comer, y antes de obedecer a los deseos de sus interlocutores, exige "el Roto" que no se le interrumpa bajo ningún pretexto, "porque en el punto que lo hagáis, en ése se quedará lo que fuere contando" (p. 335).

¿Por qué esta prevención? Según el proio Cardenio, se trata de abreviar el cuento de sus desgracias "que el traerlas a la memoria no me sirve de otra cosa que añadir otras de nuevo, y mientras menos me preguntáredes, más presto acabaré yo de decirlas, puesto que no dejaré por contar cosa alguna que sea de importancia para no satisfacer del todo a vuestro deseo" (p. 335). Pero antes de que escuchemos estas justificaciones de enamorado, Cervantes nos revela la verdadera naturaleza de la condición impuesta por el narrador: "Estas razones del Roto trujeron a la memoria de don Quijote el cuento que le había contado su escudero, cuando no acertó el número de las cabras que habían pasado el río, y se quedó la historia pendiente" (loe. cit.). En efecto, mientras aguardan la revelación del ruido del capítulo 20, Sancho ofrece entretener la espera de su amo con un relato, a condición de que lleve don Quijote cuenta de cada una de las trescientas cabras que pasan el río de la historia; cuenta mental, entiéndase, mientras procede aquél, cuya continuación nunca tiene lugar, pues don Quijote no se ha preocupado de contar las cabras, por desconocer ese modo de "consejas, cuento o historia" (p. 270) .

En el caso del cuento de Sancho se trata definidamente de un recurso cómico que sirve para desvirtuar totalmente el contenido de por sí caricaturesco de la historia, al hacerla depender de una condición totalmente externa ${ }^{8}$. También sucede esto último con la historia de Cardenio, cuya intrínseca seriedad pierde valor al quedar supeditada a una interrupción accidental: de ahí que la condición del enamorado le recuerde a don Quijote la de su escudero, porque el narrador sabe que está empleando el mismo recurso.

Sigue entonces el discurso de Cardenio, típico del enamorado cortesano; excesivamente tímido en su caso ante las dificultades que se le presentan $-\mathrm{y}$ hasta algo ansélmico en el modo en que le muestra su amada a don Fernando (p. 341) -, pero muy dentro de la retórica

7 Esta descripción no es indicio de mezcla de estilos, sino que ilustra cómo los personajes de la literatura clásica española, a diferencia de los del alto clasicismo francés y luego de los románticos, no ocultan sus necesidades vitales. También Cornelia, en la "novela ejemplar" que lleva su nombre, pide de comer antes de revelar su historia.

$8 \mathrm{Me}$ parece que el cuento interrumpido se relaciona con el recurso tradicional de contar ovejas para conciliar el sueño: el perder la cuenta significa en este caso que se ha conseguido lo propuesto, e igualmente, si don Quijote tratase de llevar la cuenta de las cabras, se olvidaría del ruido que lo preocupa. 
sentimental. El hijo del duque lee los billetes que se cruzan Cardenio y Luscinda, y con excusa de ello, pero sin duda que muy traído de los pelos (pues nada en la historia de Cardenio, que se atenía hasta ahora verdaderamente a su propia prevención de brevedad, ha pasado de lo esencial a las particularidades), se menciona el Amadis: "Acaeció, pues, que habiéndome pedido Luscinda un libro de caballerías en que leer, de quien era ella muy aficionada, que era el de Amadis de Gaula..."(p. 342) .

Es natural que Luscinda lea el Amadis, modelo de finezas de toda clase, aun cuando ya algo pasado de moda en 1605 , pero sin duda alguna que su mención tiene por único objeto interrumpir cómicamente ese relato que no podía bajo ninguna circunstancia interrumpirse: "No hubo bien oído don Quijote nombrar libro de caballerías, cuando dijo..." (p. 343). Y se lanza a una celebración del "entendimiento" de Luscinda; de suerte que cuando por fin se excusa por la interrupción y conmina a Cardenio a que vuelva a anudar el hilo de su historia, se halla con que éste tiene la cabeza caída sobre el pecho -esencialmente la reacción ya descrita por el cabrero- y en lugar de responder a su pedido, se lanza a criticar el pudor de la reina Madásima, del cual sale valedor don Quijote con la furia que caracteriza su propia locura. Pero como a Cardenio le ha sobrevenido de nuevo el "accidente" se queda mirando a don Quijote atentamente, le lanza una piedra y hace rodar por el suelo a los que intentan defender al caballero antes de volverse a la montaña ${ }^{9}$.

La variedad en la caracterización de Cardenio desde que oímos de él hasta aquí, y su actuación como loco y como amante desafortunado al mismo tiempo, resultan en que el personaje se presente siempre en relación activa con la conducta del protagonista de la novela, pero sin una dirección fija todavía: como inspiración sentimental, como imagen adicional y más salvaje de la locura, como posible caballero andariego y compañero de don Quijote (nótese que se le dan varios títulos caballerescos más o menos irónicos).

Ido Cardenio, parece como si no fuésemos a conocer la conclusión de su historia, lo mismo que la de aquella que empezó a contar el escudero, pues volvemos a concentrarnos en la relación don QuijoteSancho y sus temas característicos: deseo del escudero de hablar, verborrea refranera criticada por su amo, empeño de don Quijote en realizar alguna hazaña memorable, locuras - las mayores hasta ahoradel caballero, quejándose de amor con cabezazos contra las piedras, y culminación del tema de Dulcinea en I con la revelación de su identidad aldonzesca.

Cuando Sancho sale de la sierra, se encuentra con el cura y el barbero, y como les revela el paradero de su amo, el lector presume que

9 Es esta la primera ocasión en que Sancho olvida su cobardía o su derecho de no intervenir en peleas entre caballeros, y se lanza a defender a su señor. También al final, cuando el cabrero que cuenta la historia de Vicente de la Rosa trata de estrangular a don Quijote, sale Sancho en su ayuda (I, 52). Nótese, en relación con la caracterización que hace Gilman de Cardenio, que cuando lo posee la locura y se trata -aparte de don Quijote- de cabreros y escuderos, ataca como un león y sale vencedor. 
el final de esta segunda salida de don Quijote anda cerca. Sin embargo, transcurren aún veintiséis capítulos hasta la conclusión de la primera parte; sólo que no van llenos de las acciones del caballero lo mismo que los veintiséis anteriores, excepto por algunos incidentes en la venta, como la pelea con las botas de vino, y más tarde, ya camino de la aldea, el ataque a los disciplinantes; y tampoco de sus diálogos con Sancho, los cuales sólo readquieren momentánea profundidad cuando el caballero se encuentra preso en la jaula. Durante esta segunda mitad de la primera parte, don Quijote sólo ocupa el primer plano verdaderamente para tratar de armas y letras y de novelas de caballería (ocasión en la que lleva la voz cantante el canónigo de Toledo), y estas secuencias, junto con las de acción, apenas llenarían otro centenar de páginas ${ }^{10}$. Lo que prolonga la primera parte son las historias intercaladas casi en sucesión continua: el resto de la de Cardenio, la de Dorotea, la resolución de ambas, la novela del Curioso impertinente, la historia del Cautivo, la de su sobrina, la de Vicente de la Rosa.

Temáticamente, este predominio de la historia de intriga amorosa subraya el paralelo con la comedia, como apunta Gilman, a la vez que el alejamiento del tema central al que habían regresado las páginas anteriores (la locura caballeresca de don Quijote y su abierto y constante diálogo con Sancho). El cambio de enfoque en dirección al teatro se manifiesta externamente con el rápido disfrazarse del cura y el barbero en dama menesterosa y escudero. Tan pronto como penetran en la sierra escuchan "una voz, que sin acompañarla son de algún otro instrumento, dulce y regaladamente sonaba, de que no poco se admiraron... porque, aunque suele decirse que por las selvas y campos se hallan pastores de voces extremadas, más son encarecimientos de poetas que verdades; y más cuando advirtieron que lo que oían cantar eran versos, no de rústicos ganaderos, sino de discretos cortesanos" (p. 389).

El comentario realista sobre los verdaderos pastores no afecta la naturaleza de la historia que vamos a escuchar: mientras que su primera parte apenas pasa de introducción (7 páginas frente a 16 de la continuación en la edición Schevill y Bonilla), ésta, con la intervención de don Fernando, la de los padres de Luscinda, etc., es decididamente una novela de amores combatidos del tipo que caracteriza no ya la literatura pastoril, sino la comedia del Siglo de Oro. La artificialidad del género por el que nos internamos se halla reforzada con los ovillejos que empieza cantando Cardenio, donde alude a sus sufrimientos en un tono mucho menos directo que las quejas que halló antes don Quijote, a causa de las preguntas y sobre todo de las respuestas que preceden a los cuartetos, más dramáticos: “¿Quién menoscaba mis bienes? / Desdenes. / ¿Y quién aumenta mis duelos? / Los celos", etc. (p. 389). El soneto que sigue es aun menos alusivo al problema de Cardenio, pues aunque la falsa amistad lo afecta en cuanto a don Fernando, no es del modo general en que aparece descrita aquí.

Los suspiros del desdichado, la soledad y la hora, todo contribuye

10 En la edición Schevill y Bonilla, frente a un total de 400 páginas en el t. II. 
esta vez, contrariamente a lo que sucedía la anterior, a cimentar el marco apropiado para el desarrollo más convencional de la historia de Cardenio; pero es sobre todo la ausencia de don Quijote la que facilitará que se reanude y proceda sin interrupciones extemporáneas la novela del amante de Luscinda. Se acercan el cura y el barbero "y con breves aunque muy discretas razones, le rogó [el cura] y persuadió que aquella tan miserable vida dejase" (p. 391). Y como Cardenio estaba "entonces en su entero juicio, libre de aquel furioso accidente que tan a menudo le sacaba de sí mismo" (loc. cit.), responde muy cortésmente -después de admirarse de la presencia y traje de sus interlocutores y del conocimiento que demuestran de su negocio- con una larga explicación sobre su razón para persistir en su penar, la de otros en intentar disuadirlo, y la locura que lo posee sin él percatarse de ello, concluyendo que "no sé más que dolerme en vano y maldecir sin provecho mi ventura, y dar por disculpa de mis locuras el decir la causa dellas a cuantos oírla quieren, porque viendo los cuerdos cuál es la causa, no se maravillarán de los efectos, y, si no me dieren remedio, a los menos no me darán culpa, convirtiéndoseles el enojo de mi desenvoltura en lástima de mis desgracias. Y si es que vosotros, señores, venís con la mesma intención que otros han venido, antes que paséis adelante en vuestras discretas persuasiones, os ruego que escuchéis el cuento, que no le tiene, de mis desventuras, porque quizá, después de entendido, ahorraréis del trabajo que tomaréis en consolar un mal que de todo consuelo es incapaz" (p. 392). Razones todas tan perfectamente sentimentales que contradicen la caracterización anterior de Cardenio, al presentarlo ahora como ansioso siempre de contar su historia para ejemplo de los oyentes.

Los ansiosos interlocutores prometen "no hacer otra cosa de la que él quisiese en su remedio o consuelo; y, con esto, el triste caballero comenzó su lastimera historia casi por las mesmas palabras y pasos que la había contado a don Quijote y al cabrero pocos días atrás, cuando por ocasión del maestro Elisabat y puntualidad de don Quijote en guardar el decoro a la caballería, se quedó el cuento imperfecto, como la historia lo deja contado" (p. 393). De suerte que se continúa el relato con "el billete que había hallado don Fernando entre el libro de Amadis de Gaula [el cual] dijo Cardenio que le tenía bien en la memoria y que decía desta manera..."

Repárese en cómo el final de la primera parte de la historia de Cardenio se limitaba a mencionar el Amadis, sin especificar que hubiese dentro billete alguno. Esto subraya la distancia entre ambas partes de la misma novela en términos del progreso de la narración que las enmarca. La mención del Amadis la primera vez ocurre forzadamente, para provocar la intervención de don Quijote y el ataque de locura de Cardenio, el cual pone nuevamente de relieve su naturaleza de loco en vez de esa otra de amante que iba imperando en el curso de su relación. La segunda mención de la novela favorita del Caballero de la Triste Figura tiene lugar de un modo mucho más espontáneo -independientemente de que la mencione el narrador hablando como tal-o en relación más estrecha con las necesidades de la trama en la historia de Cardenio; es decir, que el énfasis se halla ahora en el billete 
que encuentra don Fernando en el libro pedido por Luscinda, mientras que en la primera ocasión se empezaba por el libro, que es lo menos importante, y ni siquiera se mencionaba que Luscinda lo quería para correo, o cómo llegó a manos de don Fernando. Todo lo cual tenemos que presumir al continuar Cardenio su narración, pues a Cervantes no le interesaba la primera vez sino hallar una excusa para interrumpir el cuento por vía de la locura caballeresca, y la segunda, en cambio, concluirlo sin detenerse demasiado en pormenores, de modo que podamos escuchar cuanto antes la parte de la historia correspondiente a Dorotea (la cual sigue sin interrupción a la de Cardenio y hasta comienza de modo similar, con una voz desconsolada que escucha el cura cuando se dispone a consolar a aquél). De ahí que la respuesta de Cardenio a las cortesías de sus nuevos interlocutores no consista en poner una extraña condición a la narración de su cuento, sino la más propia de la novela sentimental y como tal puramente retórica: que no traten de consolarlo.

Cardenio, en definitiva, no está ya loco, según lo prueba el modo en que se presenta a Dorotea al final de la historia de ésta, prometiendo ampararla si "con razones no le pudiese atraer [a don Fernando] a que conozca lo que os debe" (t. II, 3). En seguida hallan a don Quijote, y Cardenio, para más prueba de su cordura, aparece ante él como otro y participa en la farsa de la princesa Micomicona, asiste silenciosamente a cuanto sucede camino de la venta, a la lectura del Curioso impertinente y por fin a la resolución de su propio caso ${ }^{11}$.

La actuación de Cardenio obliga a plantearse el problema de los personajes de historias que no son parte de la acción central del Quijote, entendiendo por ésta lo que hace directamente al caballero y su escudero. La única historia - "novela" la llama específicamente Cervantes en I, 32-35, y de nuevo en II, 3 y 44- totalmente separable del texto principal, es la del Curioso impertinente, que por eso se supone hallada en un manuscrito que lee el cura en alta voz, lo que equivale a dictarla dentro del texto. Las demás, en cambio, ocurren en la fábrica misma de aquél, a través de uno o más narradores con quienes se encuentra don Quijote en el curso de sus andanzas.

Dentro de este grupo es menester establecer una escala de acuerdo con el grado relativo de contacto que se establece entre el protagonista del libro y esos narradores. El Cautivo cuenta una de las historias más complejas y vitales del Quijote, a la cual Cervantes llama "historia", "discurso de su vida", "vida y sucesos", etc. (t. II, ed. cit., 201, 202, 203, 216, 234, 264, 265), en la primera parte, pero llama sin embargo, también "novela" en la segunda: "había usado en la primera parte del artificio de algunas novelas, como fueron la del $\mathrm{Cu}$ -

11. Cervantes es bastante buen novelista como para no olvidarse del todo del Cardenio anterior, así que lo pone a punto de un nuevo ataque de locura en cuanto ove nombrar a Fernando: "se le mudó la color del rostro, y comenzó a trasudar, con tan grande alteración, que el cura y el barbero, que miraron en ello, temieron que le venía aquel accidente de locura que habían oído decir que de cuanto en cuando le venía. Mas Cardenio no hizo otra cosa que trasudar y estarse quieto, mirando de hito en hito a la labradora, imaginando quién ella era" (t. II, 15). 
rioso impertinente y la del Capitán cautivo, que están como separadas de la historia, puesto que las demás que alli se cuentan son casos sucedidos al mismo don Quijote, que no podian dejar de escribirse" (t. IV, 64; cap. 44). La razón para esta segunda categoría es que a los efectos de la estructura del Quijote, la "historia" del Cautivo es tan separable del texto central como la "novela" que la precede, porque el capitán no entra en relación con don Quijote y sus preocupaciones, limitándose, una vez narrada su conmovedora historia, a concluirla en presencia de todos, a la manera de un epílogo dramatizado en vez de contado.

El cabrero que cuenta la historia de Grisóstomo y Marcela se relaciona en cambio más activamente con don Quijote, en la medida en que éste corrige su lenguaje y celebra su cuento; éste es, al mismo tiempo, mucho más breve y artificioso que el del Cautivo, así que se destaca menos por sí solo. El narrador de la increíble historia de Vicente de la Rosa dialoga primero con el grupo de don Quijote, y una vez concluida su narración, ofende a don Quijote y pelea con él. En una categoría intermedia se hallan doña Clara, la hija del oidor hermano del Cautivo, Dorotea y Cardenio, cuyas historias suceden dentro de la narración misma, especialmente la de los amores de doña Clara y don Luis, cuyo relato y proyectada resolución ocurren entre percances de don Quijote, peleas en la venta, etc. Dorotea y Cardenio -y también, aunque en menor medida- Luscinda y don Fernando (a este último lo tenemos por un buen rato, concluida ya su historia, ayudando a don Quijote, decidiendo pleitos, etc.) son verdaderos personajes del libro, independientemente de la novela en que se hallan enredadas sus vidas, pues interactúan con don Quijote $y$ otros personajes 12 .

Lo que llama la atención en cuanto al personaje de Cardenio es la multiplicidad de facetas que ofrece antes de tener la oportunidad de completar su relación, la cual Cervantes no quiere contar de una sentada: de ahí la condición de que no se le interrumpa y la mención del Amadis. La timidez de Cardenio y lo bien caracterizada que se halla inicialmente su locura, subrayan el interés de Cervantes en la personalidad psicológica de sus personajes, en tanto que sus varios nombres, la primera condición que impone al relato de sus desgracias y la interrupción que a poco sobreviene, apuntan a ese ambiguo humor con el que Cervantes gusta de entretenernos. Paréceme, no obstante, que se trata en este caso de algo más complejo y más revelador, por lo tanto, de la estructura de la novela, según hemos tratado de probar en relación con la espontánea asociación que hace don Quijote entre la condición de Cardenio y el cuento de su escudero, y con la mención del Amadis más adelante. Una especie de indecisión de parte del novelista sobre qué hacer con el loco Cardenio, enamorado sucesivamente a lo pastoril, a lo caballeresco y a lo sentimental dentro de una acción tipo comedia; proceso que al mismo tiempo lo aleja de don Quijote, a quien empieza atrayendo como un posible doble y termina siéndole

12 Véase RiLEY, art. cit., especialmente pp. 214 ss., y más recientemente, “Teoria literaria", en Suma cervantina, Londres, 1973, pp. 313-314. 
del todo indiferente: lo recuerda sólo dos veces (pp. 349 y 351) y no da muestras de reconocerlo bajo el disfraz con que reaparece en I, $29{ }^{13}$. Indirectamente, esta vacilación respecto a Cardenio le da fuerza a su carácter, como si la timidez que revela su historia desapareciese por efecto de la locura, para volver a tomar posesión de él una vez concluido su relato, especie de catarsis que lo cura sólo para empobrecerlo como personaje; en tanto que Dorotea, después de narrar de un tirón su parte de la misma historia, sigue actuando en la de don Quijote por un buen rato, demostrando (en el papel de princesa Micomicona, en su arenga a don Fernando, etc.) la firmeza de carácter que sugería su propio relato.

En resumen, el modo en que aparece Cardenio e inicia su relación refleja en su variedad de direcciones cómo el interés en la novela sentimental-comedia de intriga amorosa que domina la segunda mitad del primer Quijote, no se halla todavía definido a esa altura del modo y al momento de la segunda aparición de Cardenio, esta vez como indudable amante cuya historia interesa verdaderamente y debe contribuir, junto con su contrapartida dorotea, un fragmento sustancial de la continuación del libro; fragmento que, sin embargo, se desarrolla del todo independientemente de don Quijote, sin tocarlo ni siquiera como testigo. Con esto queda subrayada la esencial diferencia entre ambas mitades del primer Quijote, o entre la historia del hidalgo y el complejo de materiales intercalados.

Julio Rodríguez-Luis

State University of New York at Binghamton.

\section{LA ANAFORA Y EL VERSO EXTENDIDO DE FRAY LUIS DE LEÓN}

Fray Luis nos dejó cinco sonetos, uno de los cuales está considerado entre los más bellos sonetos petrarquistas del renacimiento español.

Agora con la aurora se levanta $\mathrm{mi}$ luz, agora coge en rico ñudo el hermoso cabello, agora el crudo pecho ciñe con oro y la garganta.

Agora, vuelta al cielo pura y santa,

\footnotetext{
13 "Sigue mostrando su interés en saber más de su historia, pero no vuelve a prometer ayudarle, ni en efecto lo hace" (RILEY, art. cit. de PMLA, p. 215). El crítico reconoce la atracción que para don Quijote tiene Cardenio, por "ermitaño... loco (cual otro Amadís, otro Roldán)", p. 214; y el modo en que "con maravillosa ironía cómica Cervantes derrumba toda esta caballerosidad en farsa con la interrupción de don Quijote y la absurda pendencia", lo que atribuye a que "a don Quijote no le ha estimulado la verdadera desgracia de Cardenio como alguna bobería tocante a sus libros" (p. 215). El artículo trata precisamente de la relación entre la personalidad del protagonista y las aventuras que topa en su camino.
} 